\title{
New Ebola outbreak declared in Democratic Republic of the Congo
}

\section{Abi Rimmer}

The BMJ

The government of the Democratic Republic of the Congo (DCR) has declared a new outbreak of Ebola.

So far 17 people have died in the north west of the country, where the outbreak was declared on 8 May after two cases of Ebola virus disease were confirmed.

This is DRC's ninth outbreak of Ebola since the discovery of the virus in the country in 1976. The last outbreak was in 2017 and killed eight people.

The World Health Organization said that it was working closely with the government of DRC to increase its operations in the country and provide a response similar to that in 2017.

Allarangar Yokouide, a WHO representative in DRC, said the organisation was also working closely with other partners, including Médecins Sans Frontières, to prevent and control the spread of the disease.

The Ebola virus causes an acute, serious illness which can be fatal if untreated. The average Ebola case fatality rate is around $50 \%$. The virus is transmitted to people from wild animals and spreads in the human population through human-to-human transmission.

The 2014 Ebola outbreak in west Africa was the largest and most complicated that the world has seen. It was first identified in Guinea in March 2014 and spread to Liberia, Sierra Leone, Nigeria, and DRC, and was declared a "public health emergency of international concern" by WHO. That outbreak was declared ended in DRC in November 2014. 